\title{
Medicated Shampoo Dosage Form
}

National Cancer Institute

\section{Source}

National Cancer Institute. Medicated Shampoo Dosage Form. NCI Thesaurus. Code C91146.

A solution or suspension composed of active and inert ingredient(s) in an anionic surfactant and intended for administration to the hair and/or scalp. 